\title{
A COMPARATIVE STUDY OF PEAK EXPIRATORY FLOW RATE \& BREATH HOLDING TIME IN NORMAL \& 'OM' MEDITATORS.
}

\author{
Gayatri Bora ${ }^{1}$, Jasiya Nazir², Ravi G. N³
}

1. Assistant Professor, Department of Physiology, Adichunchanagiri Institute of Medical Sciences.

2. Post Graduate, Department of Physiology, Adichunchanagiri Institute of Medical Sciences.

3. Post Graduate, Department of Physiology, Adichunchanagiri Institute of Medical Sciences.

\author{
CORRESPONDING AUTHOR: \\ Dr Gayatri Bora, \\ Prof. Qtr - 22, B - Block, \\ Adichunchanagiri Institute of Medical Sciences (AIMS), \\ B.G. Nagara, Dist: Mandya, \\ Karnataka -571448. \\ Email : g.bora11@gmail.com
}

\section{HOW TO CITE THIS ARTICLE:}

Gayatri Bora, Jasiya Nazir, Dr. Ravi G N. "A Comparative Study of Peak Expiratory Flow Rate \& Breath Holding Time in Normal \& 'OM' Meditators ”. Journal of Evolution of Medical and Dental Sciences 2013; Vol2, Issue 23, June 10; Page: 4111-4119.

ABSTRACT: BACKGROUND: 'Om' is the name or symbol of God (Ishwara, Brahman). Either chanting or thinking about 'Om' is anecdotally reported to cause a quite mental state, and improve the all round performance of the brain and body. OBJECTIVES: The study design aimed to find the effect of 'OM meditation' on Peak expiratory flow rate (PEFR) \& breath holding time (BHT), among Non-targeted thinking (control) \& Dhyana ('Om' meditation) groups. METHODS: Source of DATA: 30 healthy male MBBS students (in the age group of 1820 years) of Adichunchanagiri Institute of Medical Sciences, B.G. Nagara, studying $1^{\text {st }}$ year MBBS, were included in the study. The group was divided equally into two sub-groups on a random basis (each sub-group consisting 15 students). Each of these sub-groups was made to get familiarized with the procedure.

I. DHYANA GROUP-performing a targeted thinking task- 'Om' meditation.

II. CONTROL GROUP-performing a non-targeted task, i.e. sitting relaxed with eyes closed.

The first phase of the recording of the pulmonary parameters i.e. PEFR \& BHT was done at the beginning of the course. The second phase of the recording was done after two months following the training. RESULTS: The DATA thus obtained was subjected to statistical analysis using student ' $t$ ' test $\&$ other relevant statistical tools to compare the changes in the measured parameters between the two groups. In the ' $\mathrm{Om}$ ' meditators, peak expiratory flow rate and breath holding time were significantly increased compared to the non meditators.

CONCLUSIONS: The present study revealed highly significant improvement in PEFR \& Breath Holding Time after consistent meditation of ' $\mathrm{OM}$ ' in experimental group as compared to control group.

KEYWORDS: 'Om' meditation; Peak expiratory flow rate (PEFR); Breath holding time (BHT). 
INTRODUCTION: Mentally chanting 'OM' leads to a single thought state \& a subjective feeling of deep relaxation. The utterance of ' $O M$ ' consisting of the 3 letters, ' $A$ ', ' $U$ ' \& ' $M$ ' comes the whole process of articulation. ' $A$ ' represents the physical plane; ' $U$ ' represents the mental \& astral plane, the world of intelligent spirit; and ' $M$ ' represents the whole deep-sleep state. This concept has been well described in various Indian scriptures. This sound represents the primal vibration from which all other sounds \& creation emerge. Scientific Studies on 'Om' suggests that the mental repetition of ' $O \mathrm{~m}^{\prime}$ results in psychological alertness, increased sensitivity as well as synchronicity of certain bio- rhythms \& an increased sensitivity to sensory transmission. $(1,2)$

An average person use only one-fourth part of lungs \& remaining $75 \%$ remains idle. In today's life of stress, which triggers, many respiratory diseases, the importance of 'Om' meditation has come to be recognized, which not only has the therapeutic but rehabilitation purpose too. It serves well for promoting relaxation, optimal lung function, emotional balance \& self-regulation of various kinds. (3)

The meditators showed a statistically significant increase in the PEFR \& breath holding time, compared to the control. Studies have observed that during both prayers \& mantras, there was increase in the synchronicity of respiratory rhythms when they were recited 6 times a minute. As references in the Bhagavad Gita goes like this - "One who is engaged in the practice of concentration, uttering the monosyllable "OM" (the Brahman or consciousness) who remember it always will attain the supreme goal." (1)

In "OM" meditation, the meditators first concentrate on a picture of "Om" \& then mentally chant mantra "OM" effortlessly; this finally leads to a state devoid of effort focusing \& is characterized by blissful awareness. Autonomic \& respiratory studies suggest that there is a combination of mental alertness with physiological rest during the practice of "OM" meditation. Therefore, we have conducted a study to see the effect of "OM" meditation on the PEFR \& BHT. (1)

METHODS: This study was conducted on 30 healthy male medical students, after due written consent. This included vegetarians as well as non-vegetarians and they led a sedentary lifestyle. There is no history of any acute or chronic illness. None of them were smokers and gave no history of alcohol intake. The volunteers were divided into two sub-groups on a random basis (each sub-group consisting 15 students).

I. “DHYANA GROUP" - performing a targeted thinking task - "OM" meditation.

II. “CONTROL GROUP” - performing a non - targeted task i.e. sitting relaxed with eyes closed.

Anthropometrical measurements including age, height \& weight were recorded. Further a preliminary clinical examination was carried out on the subject to rule out any medical problems.

The meditators were short - term i.e. meditation for 2 months. The Dhyana Group (having no earlier experience of meditation) was given supervised training for a duration of 30 minutes daily in the evening hours of which 20 minutes were spent in meditation \& the remaining 10 minutes spent in relaxation $(5$ minutes preceding the meditation \& 5 minutes 
post meditation). The subjects sat in Padmasana. Meditation involves, concentrating on the ' $\mathrm{OM}^{\prime}$ ' symbol for first few minutes and then chanting of ' $\mathrm{OM}^{\prime}$ ', while sitting comfortably with eyes closed. Whenever the mind wandered away, it was to be brought back to the visual or auditory image being used quietly and persistently. This helped one proceed to 'Dhyana', i.e. meditation.(1)

The test module was now activated and the subject was given proper instruction about the procedure to be performed. The subject, with the mini Wright's Peak flow meter mouth- piece on his mouth was asked to breathe in order to familiarize himself with the equipment. During the test the subject was adequately encouraged to perform at their optimum level and also a nose clip was applied during the maneuver. The subject was asked to take a deep breath, place the mouthpiece of the flow meter firmly between the teeth and lips and then blow out with a sharp blast. The reading on the scale was noted. Test was repeated at least 3 times at an interval of 5 minutes and the best (maximum) matching result were considered for analysis.

For the determination of BHT, the subject is sited and is asked to pinch his nostrils with the thumb and forefinger and hold his breath after a deep inspiration. The time for which the breath can be held is noted with a stop watch. Three observations are made at an interval of 5 minutes. The highest value gives the BHT in seconds for the subject.

The control group subjects are also studied in control sessions which are of the same duration as the meditation sessions and similar in design except that the 20 minutes period is spent sitting relaxed with eyes closed and non-targeted thinking (instead of meditation).Both types of sessions were repeated on 3 separate days.

Two months following the training, the PEFR is recorded in both the groups using the Wright Peak flow meter and the BHT, by using a stop watch. This was done during the morning hours (8-9 AM). The protocol was approved by the institution where the work was done and informed consent taken from the subject. All the tests were carried out at the same time of the day to avoid the possible variations, because rhythmic changes in the physiological function were found to be associated with changes in the performance during this period. The tests were done in a quiet room in order to alleviate the emotional and psychological stresses. During the tests, a maximum effort from the subjects was ensured by adequately motivating them to perform at their optimum level.

\section{STATISTICAL ANALYSIS:}

The data thus obtained is subjected to statistical analysis using student-' $t$ ' test and other relevant statistical tools to compare the changes in the measured parameters between the 2 Groups and ' $\mathrm{P}$ ' less than 0.05 were taken as significant.

RESULTS: PEFR \& BHT were significantly increased in 'OM' meditators in comparison to the control group. All 15 meditators showed statistically significant increase in PEFR \& BHT after meditation compared to the control. The mean of both respiratory parameters increased significantly.

\section{STUDY DESIGN: An Evaluation comparative study}


TABLE 1: Pre assessment of study variables

\begin{tabular}{|l|l|l|l|}
\hline PEFR L/min & Group I & Group II & P value \\
\hline Pre session & $382.00 \pm 52.90$ & $393.66 \pm 66.53$ & 0.599 \\
\hline Post session & $419.33 \pm 40.12$ & $388.66 \pm 59.20$ & 0.108 \\
\hline Difference & -37.33 & -11.96 & $<0.001^{* *}$ \\
\hline P value & $<0.001^{* *}$ & $<0.001^{* *}$ & - \\
\hline
\end{tabular}

PEFR is significantly increased in Group I (37.33) when compared to Group II (11.96) with $\mathrm{P}<0.001^{* *}$

Group I - Meditators, Group II - Non- Meditators (Control)

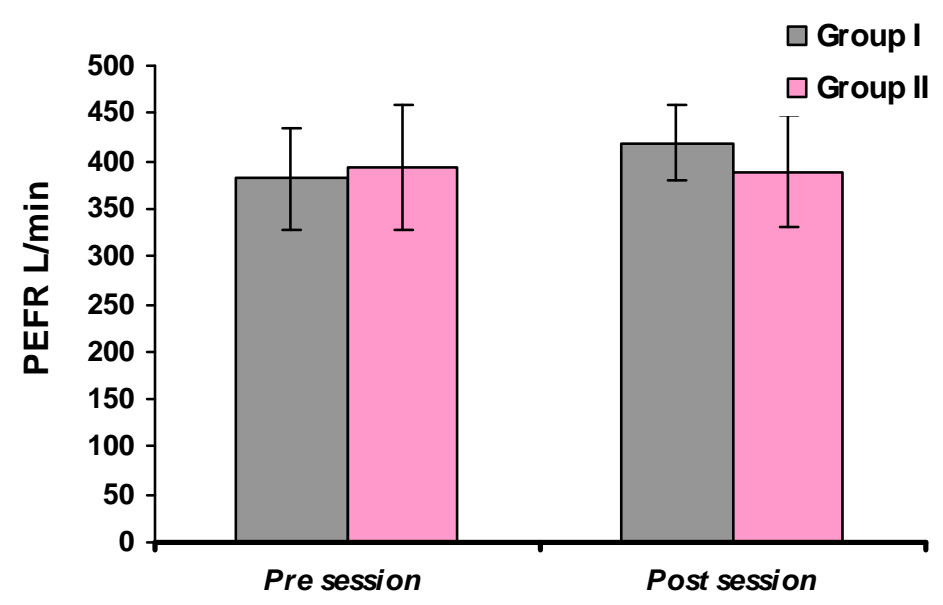

TABLE 2: Pre assessment of study variables

\begin{tabular}{|l|l|l|l|}
\hline BHT (Seconds) & Group I & Group II & P value \\
\hline Pre session & $43.67 \pm 5.68$ & $43.06 \pm 5.79$ & 0.772 \\
\hline Post session & $55.64 \pm 8.76$ & $42.46 \pm 5.45$ & $<0.001^{* *}$ \\
\hline Difference & 5.00 & 0.60 & $<0.001^{* *}$ \\
\hline P value & 0.200 & 0.499 & - \\
\hline
\end{tabular}

BHT is significantly increased in Group I (5.00 seconds) compared to Group II (0.60 seconds) with $\mathrm{P}<0.001^{* *}$ 
Group I - Meditators, $\quad$ Group II - Non- Meditators (Control)

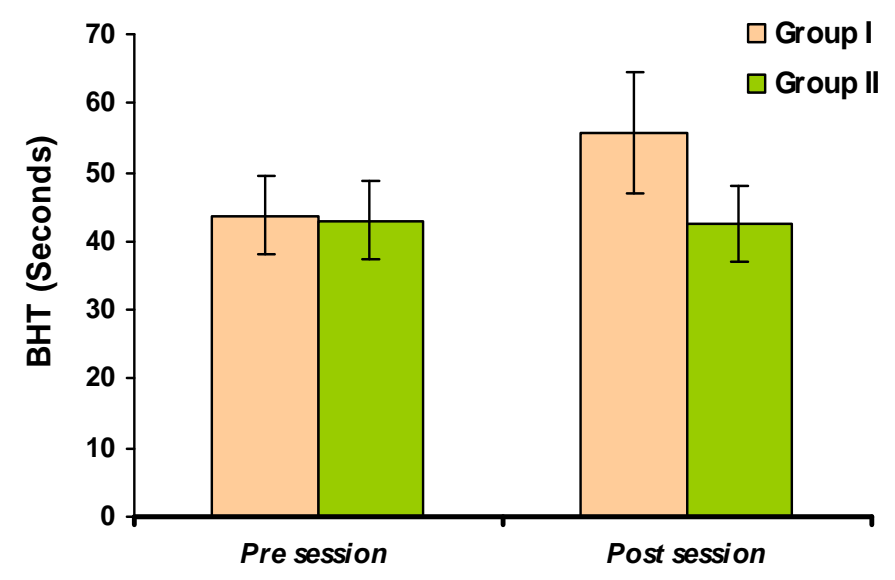

TABLE 3: Pearson correlation of PEFR and BHT in two groups studied

\begin{tabular}{|l|l|l|l|l|}
\hline \multirow{2}{*}{ PEFR vs BHT } & \multicolumn{2}{|l|}{ Group I } & \multicolumn{2}{l|}{ Group II } \\
\cline { 2 - 5 } & r value & p value & r value & p value \\
\hline Pre-session & 0.035 & 0.900 & 0.647 & $0.009^{* *}$ \\
\hline Post-session & -0.172 & 0.539 & 0.696 & $0.004^{* *}$ \\
\hline
\end{tabular}

Group I - Meditators, $\quad$ Group II - Non-Meditators (Control) 


\section{ORIGINAL ARTICLE}
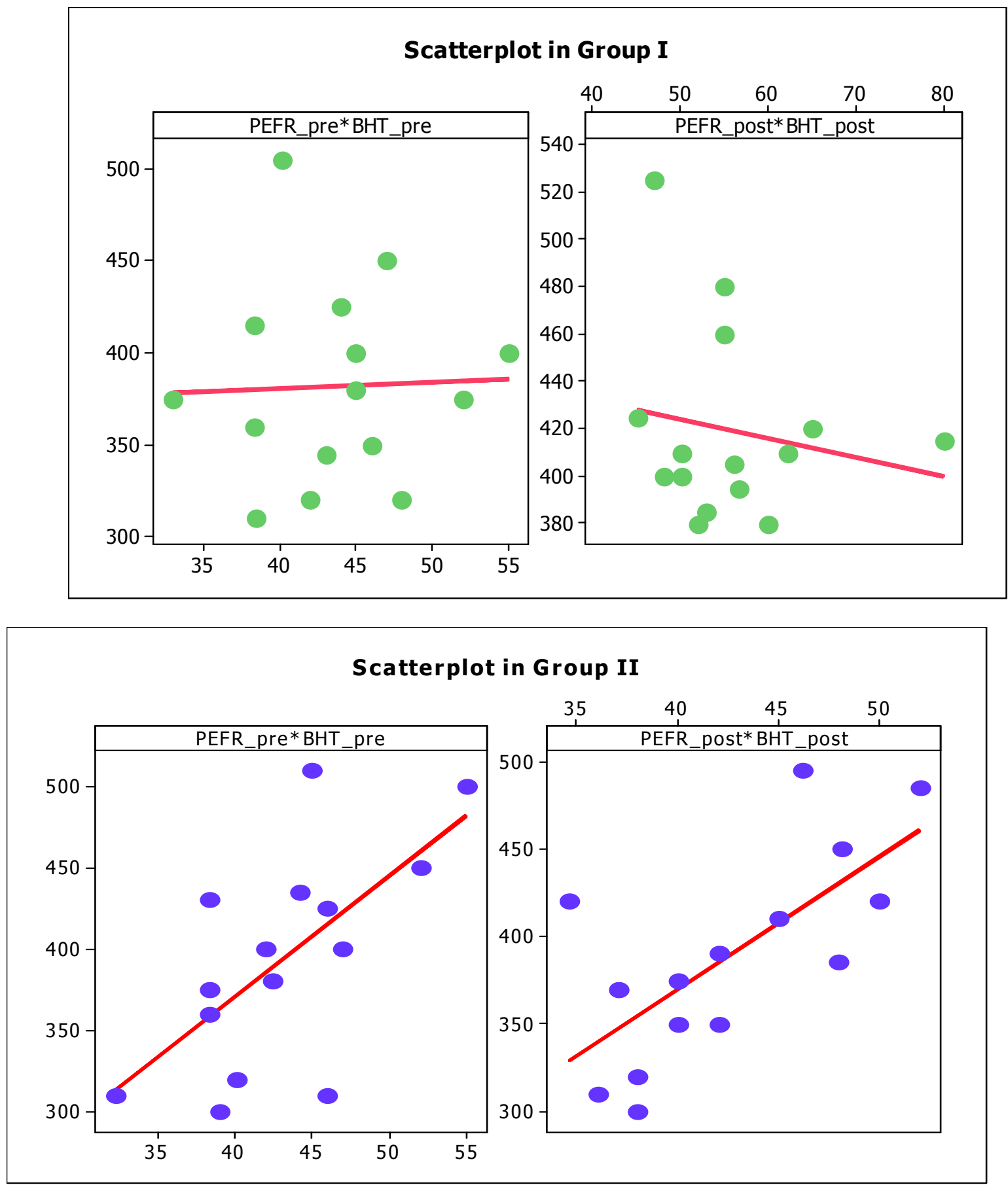

In 'OM' meditators, post session PEFR was $419.33 \pm 40.12 \mathrm{l} / \mathrm{min}$ compared to control group $388.66 \pm 59.20 \mathrm{l} / \mathrm{min}$ and breath holding time was $55.64 \pm 8.76$ seconds, compared to controls $42.46 \pm 5.45$ seconds.

Thus we can see from this study, that the results are statistically significant with $\mathrm{P}<0.05$ and there is improvement of both the respiratory variables PEFR \& BHT after consistent practice of 'OM' meditation in experimental group as compared to control group. The study suggest that practice of meditation for only a short duration of time showed an 
overall improvement in respiratory functions similar to those found in more long term studies.

DISCUSSION: In the present study, normal healthy male volunteers, who were practicing meditation on the syllable 'OM' were assessed in 2 groups, one is group I (meditators) and the other group II(control). Pre meditation recording of PEFR and BHT were taken of both the groups to make a comparative study after 2 months of meditation and see the changes if any. The result of the present study shows an increase in the PEFR \& BHT in short term 'OM' meditators.

Peak expiratory flow rate is an important parameter of pulmonary function test and it reflects mainly the caliber of the bronchi and larger bronchioles, which are subjected to reflex bronchi constriction. It is a good indicator of respiratory efficiency as it denotes the expiratory flow rate during the peak of FVC. Thus, the flow rate is a function of lung volume rather than the effort exerted, which is why it is 'effort - independent flow' and is significantly increased in 'OM' meditators.(4) The stretch receptors reflex decrease the tracheobronchial smooth muscle tone which in turn decrease air resistance and increase airway caliber, which causes the lung function test to improve. (5)

The increased PEFR can be explained on the following basis- By meditation, the rhythm of bulbo-ponto complex is slowed down and by voluntarily prolonging the phase of inspiration and expiration the respiratory muscles are stretched to their full extent and the respiratory apparatus is able to work to their maximal capacity. (6-8)

Breath holding/'voluntary apnea' which is an instructive laboratory exercise is variable for different individuals depending on the functional status of the lungs, development of respiratory muscles, practice, age and sex. (9)

BHT is increased by 'OM' meditation which is a part of Yoga training. It delays the breaking point, as it will take more time for the chemical stimuli to increase the ventilatory drive i.e. the medullary respiratory center to be stimulated. Rhythmic recitation of 'OM' can synchronize and reinforce inherent cardio-respiratory rhythms and modify chemo-receptor sensitivity. Studies have shown that there was an increase in the synchronicity of cardiorespiratory rhythms when they recited 6 times, a minute. $(1,10,11)$

Increased development of respiratory musculature and endurance due to regular practice of ' $\mathrm{OM}$ ' meditation, delays the onset of fatigue, thus allowing the breath holding for longer time. Greater lung volume decrease the frequency and amplitude of involuntary contraction of respiratory muscles there by lessening the discomfort of breath holding. $(8,12)$

It is well established that both PEFR \& BHT decreases in states of anxiety or stress and increases during relaxation and quieter mental state. (13) Studies have also proved that meditators possess a more adaptive pattern of stress response than the controls. Since the limbic system contains the hypothalamus, which controls the ANS, reduction in limbic arousal by meditation may explain how meditation reduces stress and increases automatic stability to stress. Ultimately, meditation strengthens and enhances the ability to cope with stress. $(1,13)$ 
Scientific studies on 'OM' suggest that there is a combination of mental alertness with physiological rest during the practice of 'OM' meditation. Thus, among many symbols used, 'OM' is one of the fundamental symbols used in the Yoga tradition. $(1,14,15)$

Results of studies conducted to assess the physiological effects of different meditative states i.e. meditative focusing (Dhyana), suggest that Dhyana is associated with decreased sympathetic activity and increased vagal tone, leading to rhythmic fluctuation in cerebral blood flow. Hence, correlating finding from ancient texts with contemporary science can be useful. (14-16)

Practice of meditation produce a relaxation response even in the young adult subjects who have never practiced meditation before, indicating that meditation reduces psychological stress. In our study, a greater improvement of the pulmonary parameters was observed may be because our subjects were young, healthy adults (mean age group being 19 yrs.).

We plan to extend the study in a larger population and also include more parameters, seeing to the popularity of Yoga and meditation. Yoga is indeed becoming an important and integral part to de-stress or rather a 'stress buster' in day-today modern urban life style. The results of the study were consistent with other studies which were done by Yadav A et al., Upadhyay K D et al., Chanavirut et al. and Bhargava M R et al.(12)

LIMITATION OF THE STUDY: The limitation of the present study is reduced population and lack of measurement of other respiratory parameters.

CONCLUSION: This resultant effect of ' $\mathrm{OM}^{\prime}$ ' meditation can be used as a lung strengthening tool to treat many lung diseases like asthma, allergic bronchitis, post pneumonia and tuberculosis recoveries and many occupational diseases. The results of this study and their explanation would justify the incorporation of yoga and meditation as part of our lifestyle in promoting health and thereby preventing many respiratory diseases. However it remains to be assessed whether these changes persist after resuming normal respiration and whether long term practice will lead to stable modification of respiratory control.

ACKNOWLEDGEMENT: The contribution of Dr. K. P. Suresh, Scientist (Biostatistics), National Institute of Animal Nutrition \& Physiology, Bangalore is gratefully acknowledged.

\section{REFERENCES:}

1. Sanjay Kumar, H R Nagendra, N K Manjunath, K V Naveen and Shirley Telles. Meditation on 'OM' - Relevance from ancient text and contemporary sciences. Int. J. Yoga, 2010 Jan-June; 3(1):2-5.

2. Shirley Telles, Nagarathna R, and Nagendra H. R. Autonomic changes during 'OM' meditation. Vivekananda Kendra Yoga Research Foundation, Bangalore, India. (Received on july 19, 1994)

3. Shankarappa V, NachalAnnamalai, Vinutha Shankar M.S. To compare peak expiratory flow rate and breath holding time in normal and pranayama practitioners. Indian J. of physiology and pharmacology, vol.52, no.5, 2008, pg. 207.

4. Dr. Madanmohan MD, Effect of yogic practices on different systems of human body. Professor and Head, Department of Physiology and Programme Director, ACYTER, JIPMER, Puducherry - 605006 
5. Ankad Roopa B. , Ankad Balachandra S., Herur Anita, Patil Shailaja, Chinagudi Surekharani, G. V. Shashikala. Effect of short term pranayama and meditation on respiratory parameters in healthy individuals. International journal of collaborative research on internal medicine and public health. Vol.3, No. 6 (June 2011)

6. Joshi L N, Joshi V D, Gokhale L V. Effect of short term pranayama on breathing rate and voluntary function of lungs. Indian J Physio and pharmacol., 1992; 36(2):105-8.

7. Makwana K, Khirwadkar N, Gupta HC. Effect of short term yoga practice on ventilatory function test. Indian J. Physio. And Pharmaco., 1988; 32(3):202-8.

8. Wallace R K, Benson H, Wilson AF. Awakeful hypometabolic physiologic state. Am J Physio., 1991; 221(3):795-99.

9. Lata.M. Mullar, Shrilaxmi Bagali, Jyoti.P. Khodnapur, Manjunath Aithala. Role of Short-term Yoga on pulmonary function of young \& middle aged healthy individuals. International Journal of Bio-medical \& Advance Research. Pg. 252-255.

10. Mascarenhas J F, Autonomic responses to breath holding and its variation following pranayama . Indian J Physiol and Pharmacol., 1988; 32(4):257-64.

11. Karamblekar M L , Bhole PV and Gharoke M V. Effect of yoga training on vital capacity and breath holding time. Yoga Mimimsa 1972; 14(3):19-26.

12. Shankarappa. V, Prasanth. P, Nachal Annamalai, Varun Malhotra. The short-term effect of Pranayama on the Lung Parameters. Journal of Clinical \& Diagnostic research, 2012 Feb, Vol-6 (1):27-30.

13. Yoga - mind - control.com

14. Sanjay Kumar, HR Nagendra, KV Naveen, NK Manjunath \& Shirley Telles, Brainstem auditoryevoked potentials in two meditative mental states. International Journal of Yoga.

15. Tells S, B.R. Raghavendra (2011). Neurophysiological Changes in Meditation Correlated with Description from the Ancients Texts. Biofeedback: Summer 2011, Vol.39, No.2, pp.56-59.

16. Luciano Bernardi, Peter Sleight, Gabriele Bandinelli, Simone Cencetti, Lamberto Fattorini, Johanna Wdowezye-Szulc, Alfonso Lagi. Effect of rosary prayer and yoga mantras on autonomic cardiovascular rhythms: comparative study. BMJ Vol. 323, 22-29 dec. 2001 pg. 1446-1449. 